\title{
POST-TRAUMATIC SYRINGOMYELIA: THE RESULTS OF SURGERY
}

By J. D. Vernon, M.B., B.Chir. ${ }^{1}$ J. R. Silver, M.B., B.S., F.R.C.P. Ed. \& LOND. $^{1}$ and Professor L. SYMON, T.D., F.R.C.S., F.R.C.S.E. ${ }^{2}$

${ }^{1}$ National Spinal Injuries Centre, Stoke Mandeville Hospital, Aylesbury, Bucks. HP2 I 8AL. ${ }^{2}$ The National Hospital, Queen Square, London $W C_{I}{ }_{3} B G$.

Summary. Between 1973 and 1982 twenty-seven patients with post-traumatic syringomyelia had operations performed to drain the cyst. Three types of operation were performed, cord transection, tube syringostomy to the sub-arachnoid space and tube syringostomy to the peritoneal cavity. Five patients developed proven blockage of their catheters. The results are presented. Pain was dramatically and gratifyingly improved in 14 patients. Motor power showed the most consistent improvement in I 4 patients. Only eight patients showed sensory improvement; this was the least likely to improve. The progress of the condition could be arrested in the majority of cases, but a small number continued to deteriorate and required further operations.

Key words: Post-traumatic syringomyelia; Results of surgery.

\section{Introduction}

POST-TRAUMATIC syringomyelia has recently been recognised as a complication of spinal injury (Bastian, I867; Strumpell, I 880; Holmes, I9I 5; Freeman, 1959; Finckel, I960; Gardner, I965; Barnet et al., I966; Shannon et al., I98I; Vernon et al., I982). Operations have been performed upon the cyst to try an modify the progress of the condition and relieve the symptoms. It is the purpose of this study to review the results of surgical treatment in 27 patients.

\section{Method of Study}

We know of over 50 patients with post-traumatic syringomyelia. All patients in whom we made the diagnosis were referred for investigation, apart from two who died before the surgical era, one who lived in Scotland, one who lived in Ireland, one who was too old, and one who was too ill.

Two patients attended a neurosurgical centre but declined to have further investigations.

\section{Patients}

Twenty-three of the patients were investigated and operated upon at the National Hospital for Nervous Diseases, Queen Square. Four patients were treated elsewhere, two (J. D. \& P. W.) at Oxford, one (R. R.) at Sheffield, and one (C. H.) at Birmingham. The clinical details of 24 patients have been presented in a previous publication (Vernon et al., 1982). The details of a further three patients are presented in the accompanying Table I. 


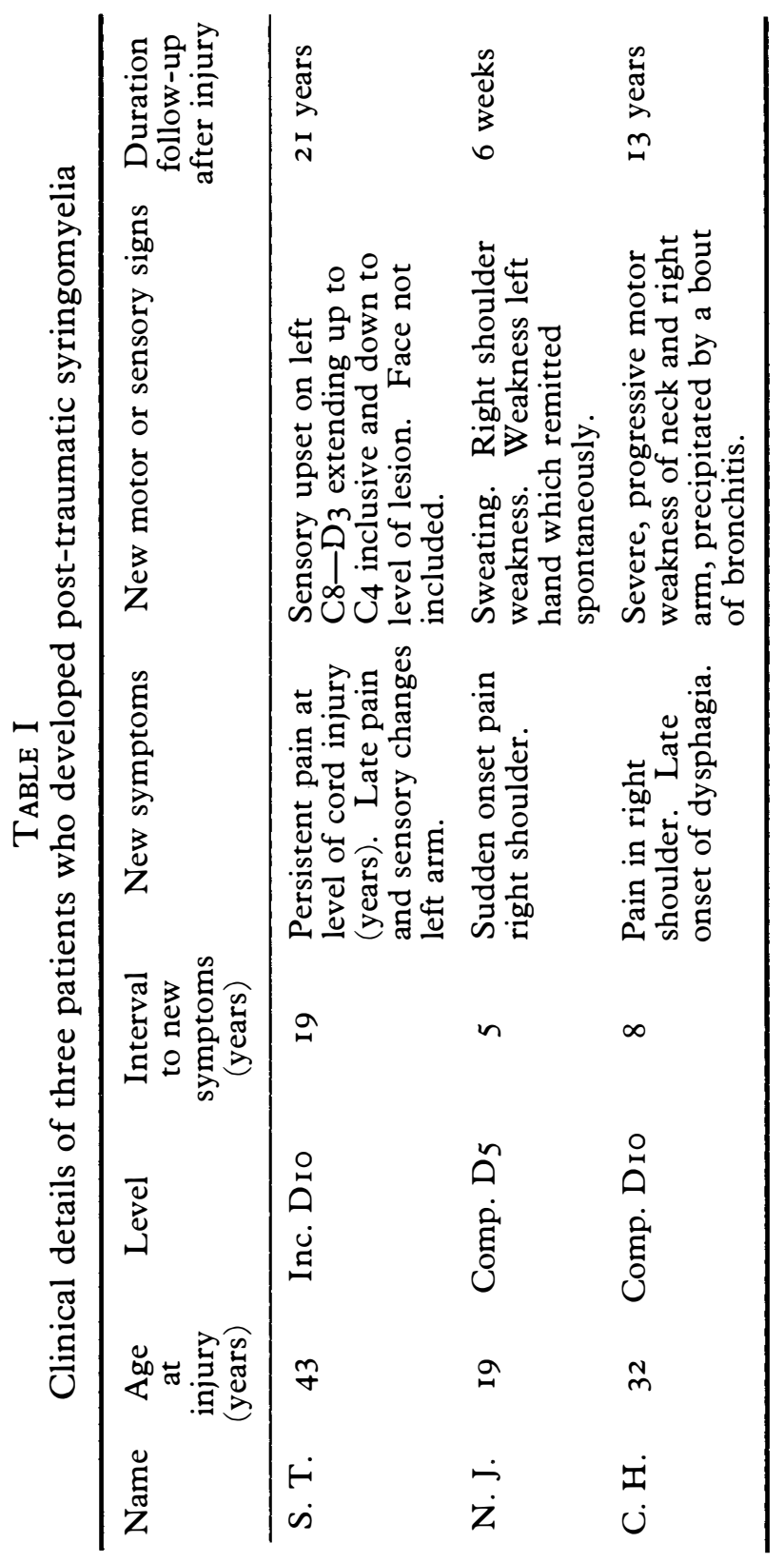


Follow-Up

Twenty-four patients were followed up at the National Spinal Injuries Centre for a minimum of five weeks and a maximum of five years and ten months, apart from (B. H., E. F. who were lost to follow-up, Table II and J. D.).

TABLE II

Details of the operation

\begin{tabular}{|c|c|c|c|}
\hline Name & Operation & Date & Follow-up \\
\hline R. P. & $\mathrm{S}+$ cath & I 976 & 5 years \\
\hline R. S. & $S$ & January I 978 & 3 years \\
\hline B. $\mathrm{H}$. & $S+$ cath & June I 978 & Lost to follow-up \\
\hline T. G. & $\mathrm{S}+$ cath & May I 980 & 9 months \\
\hline W. W. & $S+$ perito & October 1979 & I yr. 8 mths. \\
\hline K. T. & Transection & March 1977 & 3 yrs. 3 mths. \\
\hline J. R. & Cord incision & January I 975 & 3 yrs. 3 mths. \\
\hline A. A. & Cord incision & July I 975 & 3 years \\
\hline D. R. & $S+$ perito & May I980 & Io months \\
\hline D. K. & Incision & I 976 & I year \\
\hline \multirow[t]{2}{*}{ T. M. } & $S+$ cath & October I 980 & I yr. 6 mths. \\
\hline & $\mathrm{S}+$ perito & January I 982 & - \\
\hline S. K. & $S+$ cath & October I980 & 4 months \\
\hline G. V. & $\mathrm{S}$ & May I975 & 5 years \\
\hline P. W. & Cord transection & $\begin{array}{l}\text { May I } 979 \\
\text { Oxford }\end{array}$ & 2 yrs. 9 mths. \\
\hline A. B. & $S+$ cath & I978 & 2 years \\
\hline \multirow[t]{2}{*}{ J. D. } & Aspiration & $\begin{array}{l}\text { April I } 977 \\
\text { Oxford }\end{array}$ & Lost to follow-up \\
\hline & $\mathrm{S}+$ cath & $\begin{array}{l}\text { April i } 980 \\
\text { Oxford }\end{array}$ & \\
\hline \multirow[t]{2}{*}{ S. I. } & $S+$ perito & August I 980 & $\mathrm{I} \frac{1}{2}$ years \\
\hline & $S+$ perito & August I98I & 8 months \\
\hline R. R. & Cord excision & I976 Sheffield & December I 98 I \\
\hline P. B. & Transection & October I 976 & 4 yrs. 2 mths. \\
\hline J. Re. & $\mathrm{S}$ & May 1980 & Io months \\
\hline \multirow[t]{2}{*}{ J. H. } & $\mathrm{S}+$ cath & August I978 & 2 years \\
\hline & $S+$ perito & February 1982 & 5 months \\
\hline E. F. & $\begin{array}{l}S+\text { perito } \\
S+\text { cath }\end{array}$ & $\begin{array}{l}\text { I } 979 \\
\text { I } 980\end{array}$ & Lost to follow-up \\
\hline D. E. & $\mathrm{S}+$ cath & December I980 & \\
\hline J. Mc. & $S+$ cath & November I 979 & I yr. 6 mths. \\
\hline S. T. & $S+$ perito & March I98I & 6 months \\
\hline N. J. & $S+$ perito & October I98I & 6 weeks \\
\hline C. H. & Cord transection & December I98 I & 2 months \\
\hline
\end{tabular}

$\mathrm{S}=$ Syringostomy

cath $=$ Catheter to subarachnoid space

perito $=$ Drainage into peritoneal cavity 


\section{Investigations}

Routine plain X-rays of the spine were carried out at the National Spinal Injuries Centre.

Specialized views of the cervical spine were frequently necessary in the neurosurgical centre, since the differential diagnosis of advancing symptomatology in patients with spinal trauma include degenerative spinal disease at a higher level, in particular cervical spondylosis.

The specific investigation of post-traumatic syringomyelia has for many years been myelography with oily or water soluble contrast media. Initially, oil or air contrast was employed in an endeavour to demonstrate expansion of the cord above the level of the trauma, and alteration in its calibre with change in posture. In a number of instances (Kendall and Symon, I973) the procedure of endomyelography was employed, a fine needle being introduced, usually in the upper dorsal level, into the centre of the spinal cord and a small injection of oil or water soluble contrast medium into the cystic cavity in the cord was carried out. This manoeuvre in some instances is associated with transient resolution of pain, and indeed its employment (Booth and Kendall, I970) in cases of true idiopathic syringomyelia, was one of the stimulii to the development of drainage procedures for a post-traumatic syrinx. Most recently however, water soluble contrast, (Metrizamide) had been employed to outline the spinal cord above the level of the trauma, introduced either by lumbar or more frequently by a cisternal injection, and this has been followed by CT scanning at about 6 and 24 hours. We have found that Metrizamide commonly diffuses into the cavity of the syrinx, and CT scanning of the cervical and upper thoracic region will reveal the characteristic density of the syrinx, without the necessity to puncture the spinal cord itself (Gentili, Davis and Symon-in preparation).

\section{Surgical Management}

In the present series of cases, three forms of surgical treatment have been employed.

I. Cord transection

2. Tube syringostomy from the cyst to the subarachnoid space

3. Tube syringostomy from the cyst to the peritoneal cavity using a Raimonde low pressure valve system.

The technique of cord transection was earliest employed, but is, of course, applicable only to patients with complete paraplegia. In addition, we have not been satisfied that cord transection invariably results in satisfactory drainage of the cyst over a prolonged period of time, since arachnoid adhesions tend to form and occasion reaccumulation of fluid within the cord. As the necessity of drainage of cysts in incomplete paraplegics became apparent, the operation of tube syringostomy was commonly performed. This operation was customarily performed, some segments proximal to the level of trauma, usually at the $\mathrm{T} 3-4$ level. In patients with cervico-dorsal injury however, tube syringostomy could be performed at any level of the cervical spine. The operation is performed through a midline incision, and a small laminectomy of $2-3$ vertebrae, the 
dura being opened under the microscope and dissection pursued through the thin posterior columns to expose the central glial cavity. The cavity is drained by the insertion of the ventricular end of a small Pudenz catheter into the cavity, cephalad for a distance of $4-5 \mathrm{cms}$. The catheter is anchored by an encircling stitch to the deep surface of the dura, and its distal end led down anterior to the denticulate ligament into a conveniently patent area of the subarachnoid space. The occasional difficulty due to extensive adhesions in the subarachnoid space and an apparent tendency for blockage of the subarachnoid portion of the catheter, has led to the development of the operation of syringo-peritoneal shunt. Revision of tube syringostomy can be a difficult procedure, and this operation has now been replaced routinely by an operation to lead the distal end of the catheter through the carefully closed dura, anchored in the muscles by the medium of a metal connector, to the armoured catheter of the Raimonde low pressure drainage system. The tubing is led down into the flank, the laminectomy wound closed, and the patient turned to expose his abdomen. A small midline or oblique right subcostal incision is then made, and the catheter is picked up in the flank incision, and led round into the abdomen. A suitable length of catheter is placed in the abdomen. The results of this procedure which has become the routine method of surgery, are currently being evaluated.

\section{Complications}

In one patient wound breakdown occurred, necessitating secondary closure of the wound.

Two patients developed C.S.F. leaks requiring serial lumbar punctures. Five patients developed signs of catheter blockage with neurological deterioration and have been re-operated on to revise the drainage of the cyst. (One is awaiting revision).

\section{Results}

The results are presented in Table III. We have concentrated mainly on the results of the first operation though subsequent operations are discussed where appropriate.

Pain

Pain is a very difficult symptom to describe, especially in paraplegic patients, as they may suffer from several forms of pain.

I. There are organic forms of pain due to such conditions as frozen shoulder, fibrositis or arthritis in the normal or partially denervated upper limbs. These conditions are particularly common in paraplegic patients as these limbs are taking an excessive load, the arms doing the work of the paralysed lower limbs. In addition there is pain at the fracture site due to long standing local tissue damage.

2. There is central pain in the neck which radiates down the arm, and which may be aggravated by coughing and straining.

3. There is pain at the level of the lesion which is not affected by coughing and straining and has, in the past, frequently been diagnosed as root pain. 
TABLE III

Results of surgery

\begin{tabular}{|c|c|c|c|c|c|c|}
\hline Name & Pain & Sensory & Motor & $\begin{array}{l}\text { Bladder } \\
\text { function }\end{array}$ & $\begin{array}{l}\text { Bowel } \\
\text { function }\end{array}$ & $\begin{array}{c}\text { Sexual } \\
\text { function }\end{array}$ \\
\hline R. P. & ++ & + & ISQ & ISQ & ISQ & ISQ \\
\hline R. S. & + temp & - & - & ISQ & ISQ & ISQ \\
\hline $\begin{array}{l}\text { B. H. } \\
\text { T. G. }\end{array}$ & $\mathrm{O}$ & ISQ & $\overline{+}+$ & ISQ & ISQ & \\
\hline W. W. & ISQ & + & ++ & & & \\
\hline $\mathrm{K} . \mathrm{T}$. & $\mathrm{O}$ & +++ & + & ISQ & ISQ & ISQ \\
\hline J. R. & ISQ & ISQ & + & ISQ & ISQ & ISQ \\
\hline A. A. & $\stackrel{+}{+}$ & ISQ & + & ISQ & ISQ & ISQ \\
\hline $\begin{array}{l}\text { D. R. } \\
\text { D. K. }\end{array}$ & $\mathrm{O}$ & & ISQ & ISQ & ISQ & \\
\hline D. K. & $\mathrm{O}$ & $\begin{array}{l}++ \text { followed } \\
\text { by deterioration }\end{array}$ & + & ISQ & ISQ & \\
\hline T. M. & + & $-\cdots$ & - & - & ISQ & ISQ \\
\hline $\begin{array}{l}\text { S. K. } \\
\text { G. V. }\end{array}$ & $\begin{array}{l}+ \\
+\end{array}$ & $\begin{array}{l}+ \\
-\end{array}$ & $\begin{array}{l}+ \\
+\end{array}$ & $\begin{array}{l}\text { ISQ } \\
\text { ISO }\end{array}$ & ISQ & ISQ \\
\hline P. W. & ISQ & - & $\begin{array}{l}\text { ISO } \\
\text { ISQ }\end{array}$ & ISQ & $\begin{array}{l}\text { ISQ } \\
\text { ISQ }\end{array}$ & d ISO \\
\hline A. B. & & $-\mathrm{LL}$ & ISQ & ISQ & ISQ & ISQ \\
\hline J. D. & $\begin{array}{l}\text { Temp - } \\
\text { post-op }\end{array}$ & + & + & & & \\
\hline S. I. & $\begin{array}{l}+ \text { Comp. } \\
+ \text { Partial } \\
\text { perm. }\end{array}$ & - & - & - & ISQ & ISQ \\
\hline $\begin{array}{l}\text { R. R. } \\
\text { P. B. }\end{array}$ & + & - & ISQ & - & - & - \\
\hline $\begin{array}{l}\text { P. B. } \\
\text { Re. }\end{array}$ & + temp. & -- & ISQ & & & \\
\hline $\begin{array}{l}\text { Re. } \\
\text { J. H. }\end{array}$ & ++ & & Transient & ISQ & ISQ & ISQ \\
\hline $\mathrm{H}$ & + & - & - & ISQ & ISQ & ISQ \\
\hline E. F. & - & ISO lost & $\begin{array}{l}+ \\
-\end{array}$ & ISQ & ISQ & ISQ \\
\hline & + & to follow & + & & & \\
\hline & & & & & & \\
\hline D. E. & 0 & $\begin{array}{l}+ \text { followed } \\
\text { by - }\end{array}$ & $\begin{array}{l}+ \text { followed } \\
\text { by - }\end{array}$ & & & \\
\hline J. Mc. & + & + & + & ISQ & ISQ & ISQ \\
\hline $\begin{array}{l}\text { S. T. } \\
\text { N. J. }\end{array}$ & $\stackrel{+}{0}$ & $\overline{\mathrm{O}}$ & $\begin{array}{lll}+ \\
+\end{array}$ & ISQ & ISQ & \\
\hline C. H. & ++ & ++ & + & ISQ & ISQ & - \\
\hline
\end{tabular}

$+=$ Improvement

$++=$ Marked improvement

$-=$ Deterioration

$--=$ Marked deterioration

L.L. = Lower limbs

temp $=$ Temporary

$\mathrm{O}=$ No change

4. Pain below the level of the lesion of the phantom type.

Pain from a cyst was the commonest presenting feature and the one most amenable to surgery. It was the central type ${ }^{2}$ or at the level ${ }^{3}$ of the 
lesion that we are particularly concerned with here. Other forms of root pain and phantom pain 4 are unlikely to respond.

Fourteen patients showed a lasting amelioration of the symptoms ranging from improvement to complete relief. One patient who had no pain pre-operatively developed pain post-operatively for a short period. Fourteen patients who had no pain pre-operatively remained free of pain postoperatively. Three patients had no change.

Relief was very striking when it occurred. Some noticed relief when they recovered from the anaesthetic. Failure or relapse has been shown to be due to a blocked catheter and now all the cases that have deteriorated are being reviewed in the belief that the deterioration is due to further accumulation of fluid in the cyst. One patient, (S. I.) was well for a month after his syringo-peritoneal shunt and then the pain recurred, and motor and sensory deterioration were observed. It was some months before the recurrent cyst could be demonstrated during which time his condition became appreciably worse. A second operation did not return him to the satisfactory state that he was in following the first operation.

Patient (G. V.) had a complete Drz lesion. He had two forms of pain; one a stabbing pain in his scrotum and groins radiating between his legs, and this was his main disability for some years. He developed severe drilling neck pain. This latter pain disappeared following surgery to drain the cyst, but the pain in his scrotum became more prominant and became his main complaint once more.

In contrast patient (S. T.) aged 43 had a lesion at Dio. He had had pain at the level of his lesion for years, and then developed pain in his neck and shoulder which was diagnosed as cervical spondylosis until sensory loss was observed and the diagnosis of syringomyelia was made. Postoperatively he had complete relief of the pain at the level of the lesion, but the shoulder pain resolved much more slowly.

Patient (J. Re) who had a complete lesion at D6 developed severe pain in the left shoulder with associated spino-thalamic loss. Drainage of the cyst relieved the shoulder pain but he was left with some tender areas which were relieved by injections of local anaesthetic. There are thus more than one pathway for the pain peripherally.

One patient (J. D.) developed pain for the first time after surgery. Fortunately it was not severe and it did not last long.

Pain was the symptom that the patients complained of most preoperatively, they were most grateful for the relief and stated that the procedure was worth having for this alone and they were willing to have the operation repeated when the pain recurred, showing how effective the pain relief was.

\section{Motor Function}

Following operation I 4 patients had improved motor function; 4 showed no change, 6 patients deteriorated but then had further operations and improved. Three patients have deteriorated and have not been re-operated upon. In the 14 patients who improved, the improvment was not dramatic but was only an increase of about one point on the MRC scale and was usually reported by the patient as an increase in the strength of grip. Thus T. G. had global weakness of the right hand with associated sensory loss. 
Post-operatively the grip improved although the sensory loss ascended two segments. Two patients who deteriorated had a return of pain. Both patients improved following a second operation. A further patient only noticed the weakness retrospectively when the operation resulted in improvement.

\section{Sensory Function}

Eight patients improved after the first operation, two were the same, I I deteriorated. Two patients had two operations. Patient (S. I.) had no immediate change after the first operation but deteriorated when the shunt blocked. He improved after the second operation but did not return to the state achieved immediately after the first operation. Patient (K. T.) had sensory loss from $\mathrm{C}_{3}-\mathrm{D} 6$ on one side, and post-operatively completely recovered all modalities of sensation to D6 and became normal again. He is the only patient whom we have seen who has made a complete sensory recovery. Patient (T. G.) had sensory deterioration following surgery and the level ascended $\mathrm{I} \frac{1}{2}$ segments, although motor power returned completely to normal.

\section{Bladder, Bowel and Sexual Function}

No patients showed any change in their bladder, bowel or sexual functions.

\section{Discussion}

The surgical treatment of post-traumatic syringomyelia was first described by Barnett et al., I973. Initially they carried out a transection of the cord at the level of the injury to allow the cyst to drain freely. Subsequently they developed a technique of also inserting a catheter, Shannon et al. (I98I) have given a full description of the surgical treatment. Tator et al. (I982) have described excellent results in four patients. It is not the purpose of this paper to discuss the surgical technique, but to concentrate on the results and the follow-up of surgical intervention.

Operative treatment is comparatively recent. The first operation in this series was carried out in I975. Initially the cord was transected, but the results were unpredictable, the problem being that the arachnoid tended to seal up the drainage of the cyst. For this reason this operation was abandoned and the cysts were drained more formally by a catheter into the subarachnoid space. The problem of the arachnoid also sealing off the catheter still remined. To avoid this the operation of syringoperitoneal shunt was devised, the catheter draining into the peritoneal cavity.

Clinical deterioration has been assumed to be due to blockage of the drain, with the reaccumulation of fluid within the cyst causing pressure upon the surrounding structures. The diagnosis is easy when the clinical deterioration is the re-occurrence of pain; but in some patients deterioration occurred without any pain occurring.

The result of the operation has usually been beneficial. It stops the pain, relieves some of the symptoms and in some patients arrests the progress of the condition. As yet it is impossible to predict which patients will benefit, and some indeed deteriorate after surgery. However a study of 
the natural history of the condition and those patients who have benefitted from surgery may provide some further information and some tentative conclusions.

The exact relationship of the cyst or cysts to the motor or sensory loss is not easily explained on anatomical grounds. The cyst is commonly found at the base of the posterior horn at quite a distance from the motor fibres and the posterior columns and it is thus easy to understand why motor involvement should be late, and involvement of the posterior columns very rare.

The signs and symptoms may be less related to the size and location of the cyst then to the speed of growth and tension within the cyst, since one patient (D. E.) had a large cyst but only minimal motor loss, while other patients have had severe manifestations with little, if any, radiological evidence of cyst formation.

Motor power has shown the most consistent improvement. It is commonly a late manifestation and thus the motor fibres which have been compressed for the shortest period of time, will be the most likely to improve.

Posterior column loss is very rare and can similarly be explained because of their considerable distance from the site of cyst formation. However, other features such as the speed of growth and tension within the cyst seem to be important since if the sensory loss takes place very slowly, such as in the case of $(\mathrm{K} . \mathrm{T}$.), there is a greater chance of improvement than when there is a dramatic overnight deterioration (T. G.), a slow onset would indicate pressure but a rapid onset is indicative of destruction. This is in common with other compression lesions of the spinal cord.

We have seen from post-mortem examinations that multiple cysts may be present. This has been confirmed by myelography $(\mathrm{K})$. That they need not intercommunicate has been demonstrated by one patient in the series, when at operation three cysts were found by needling, the fluid from each aspiration having a different specific gravity. One questions, therefore, whether the deterioration which occurred may be due to a fresh cyst forming or to the catheter failing to drain all of the cysts at once.

One patient, (R. R.) had cord excision performed to relieve pain. This was in part successful although the location of the pain which ultimately returned was different. In addition he had the clinical picture seen classically in syringomyelia. The lower end of the cord which was removed was cystic. It may be that cord transection for pain, which is sometimes very successful, acts as a cyst drainage operation.

\section{Conclusion}

Symptoms of pain in post-traumatic syringomyelia can be dramatically relieved by drainage of the cyst. Motor weakness is the most consistent sign to be improved. The progress of the condition can be altered. However, the follow-up in this series is insufficient to determine whether this is permanent. In a small number of patients the condition has continued to progress. As a working hypothesis it has been assumed that surgical drainage was impaired and that this could be improved by a further operation. It is too early to say if this hypothesis is correct. However, it is clear that failure to operate will inevitably, sooner or later, lead to progressive and severe disability. 


\section{RÉSUMÉ}

27 cas de syringomyélie post-traumatique ont été opérés par drainage chirurgical du kyste, entre I973 et I982. Trois types d'intervention furent réalisés: Trans-section médullaireSyringostomie par drainage dans l'espace sous-arachnoïdien-Syringostomie par drainage dans la cavité pépitonéale. Cinq fois, survint une obstruction du drain. Les résultats sont présentés. La douleur fut nettement et valablement améliorée ches I4 patients. L'amélioration motrice fut dominante dans.

I 4 cas. Seule, une amélioration de la sensibilité fut constatée dans 8 cas, mais dans une moindre proportion. L'aggravation du processus fut arrétée dans la majorité des cas mais quelques cas continuérent á se détériorer et pour ceux-ci d'autres interventions furent nécessaires.

\section{ZUSAMMENFASSUNG}

Zwischen I973 und 1982 wurden 27 Patienten mit Post-traumatischer Syringomyelie an eine Kysteentfernung operiert. Drei Operationsarten wurden ausgeführt; Chordotomie, Syringostomie-drän zum subarachnoidalen Raum und Syringostomiedrän zum peritonalen Kavum.

Bei 5 Patienten trat eine Kathetersperrung auf. Die Ergebnisse ziegten, dass bei I4 Patienten der Schmerz sehr wirksam erleichtete.

Bei I 4 Patienten zeigte sich beständige Verbesserung der Motorik. Nur 8 Patienten zeigten Verbesserung der Sensibilität, dies war der minimal zu erwarten Verbesserung.

In die meiste Fälle konnte eine Progression der Kondition festgestellt werden, aber eine kleine Zahl blieb rückgängig und erförderte erneute Operation.

\section{REFERERENCES}

Barnett, H. J. M., Bottrell, E. H., Jouse, A. T., Wynn Jones, M. (i966). Progressive myelopathy as a sequel to traumatic paraplegia. Brain I 966, 89, I 59-I 74.

Barnett, H. J. M., Foster, J. B., Hudgson P. (I973). Syringomyelia. Major Problems in Neurology, Vol I, pp. 3 I 8 . W. B. Saunders, London/Philadelphia/Toronto.

BAstian, H. C. (I867). On a case of concussion-lesion with extensive secondary degeneration of the spinal cord. Proceedings of the Royal Medical and Churirgical Society of London, 50: 499.

Booth, A. E., Kendall, B. E. (I970). Percutaneous aspiration of cystic lesion of the spinal cord. F. Neurosurg., 33, I 40-I 44.

Finckel, J. R. (I960). Lesions ascending from spinal cord injuries. Proc. Ninth Ann. Clin. Sp. Cord Inj. Conf. pp. 45-48.

Freeman, G. (I959). Ascending spinal paralysis. F. Neurosurg., 16, I 20-I 22.

GARDNER, W. J. (I965). Hydrodynamic mechanism of syringomyelia: its relation to myelocele. F. Neurol., Neurosurg., Psychiatry, 28, 247-259.

Gentili, F., Davis, C. D., Symon, L. (In preparation).

Holmes, G. (I9I5). The Goulstonian Lecture on Spinal Injuries of Warfare. British Medical fournal, 2, 769-774.

Kendall, B., Symon, L. (I973). Cyst puncture and endomyelography in cystic tumours of the spinal cord. Br. F. Radiol. 46, I98-204.

Shannon, N., Symon, L., Logue, V. et al. (I98I). Clinical features, investigation and treatment of post-traumatic syringomyelia. $\mathcal{F}$. Neurol., Neurosurg., Psychiatry, 44, 35-42.

Strumpell, A. (I 880). Beitrage Zur Pathologie Des Ruckenmarks. Archives Fur Psychiatrie Und Nervenkrankheiten, I0, 676.

Tator, C. H., Meguro, K., Rowed, D. W. (I982). Favorable results with syringosubarachnoid shunts for treatment of syringomyelia. F. Neurosurg., 53, 517-523.

Vernon, J. D., Silver, J. R. \& Ohry, A. (I982). Paraplegia, 20, 339-364. 